\title{
NEW TRENDS AND TOPIC CHANGES OF JBEM 2007-2019: A BIBLIOMETRIC REVIEW
}

\author{
Xintu LEI(1)*, Qingyuan XU(1) \\ College of Management, Zhejiang University of Technology, Hangzhou, China
}

Received 03 December 2019; accepted 21 October 2020

\begin{abstract}
The Journal of Business Economics and Management (JBEM) has been very active in the field of economics and management science and brought many influential outputs in the last decades. This paper investigated the current status of publications and citations from JBEM and explored the hot topics and new trends represented by most used keywords extracted from the published articles from 2007 to 2019. The data were analyzed and mapped with respect to the most cited literature, most prolific authors, and publication records categorized by authors, institutions and countries. The analysis revealed that papers published each year by the JBEM is relatively stable and published papers has an expected citation number 7.68 times. The difference in frequency of keywords in different stages give us informative clue for future studies. The emerging topics include "SMEs" "Information" "framework" "perspective", hence the likely focus of JBEM to consider submission of papers centered on these topics, the comparison of keywords between JBEM and Hot Papers \& Highly Cited Papers was made as well. Some new trends, for example, information science combining with management science are new hot topics.
\end{abstract}

Keywords: topics change, keywords co-occurrence, bibliometric analysis, Journal of Business Economics and Management, Web of Science, knowledge visualization.

JEL Classification: Y10, Z19.

Online supplementary material: Supporting information for this paper is available as online supplementary material at https://doi.org/10.3846/jbem.2021.13885

\section{Introduction}

During the Soviet-era, Lithuania adopted a socialist planned economy. After Lithuania's separation from the Soviet Union in 1990, social liberalization in the post-Soviet period stimulated economic development and economic activity (Statistics Lithuania, 2013). During this period, Lithuania has made significant progress in business practice and business education system, identifying the direction of Lithuanian education and research (Pranulis, 2004). The

*Corresponding author. E-mail: amok23@163.com

Copyright (c) 2021 The Author(s). Published by Vilnius Gediminas Technical University

This is an Open Access article distributed under the terms of the Creative Commons Attribution License (http://creativecommons. org/licenses/by/4.0/), which permits unrestricted use, distribution, and reproduction in any medium, provided the original author and source are credited. 
Journal of Business Economics and Management (hereinafter referred to as JBEM), is one of the renowned Lithuanian journals in this field.

The JBEM, started publishing in 1999, is an international open access peer-reviewed journal and published quarterly by Vilnius Gediminas Technical University. The journal addresses the important topics in business, management and economics: Global Business, Transition Issues, Economic Growth and Development, Economics of Organizations and Industries, Finance and Investment, Strategic Management, Marketing, Innovations, and Public Administration. It publishes research articles and reviews. Today, JBEM is a leading economics journal with an impact factor (IF) of 1.5, ranking as 94th among 140 publications in categorize in business and 122nd from 353 journals in economics according to the 2018 Journal Citation Reports released by Clarivate Analytics.

In the recent 12 years, JBEM had published 670 papers (as of December 31, 2019), received 4853 citations in Web of Science (annual value are graphed in Figure 1). These values provide us a viable indicator for bibliometric analysis, giving forthcoming author a clear performance and impact in the field of business and economics, and serve as a unique basis of analysis to study the evolution of the key themes and topics addressed by the journal.

Bibliometric is developed as a discipline combining with information science, computer science and knowledge management (Aksnes \& Sivertsen, 2004). It provides series of tools to evaluate research development in scientific publications, scholars outputs, country performance (Andres, 2010; Lei $\& \mathrm{Xu}, 2020$ ) by the quantitative characteristic of literature and visualization in text mining. From the survey of the literature available in the Web of Science, the publications employing bibliometric can generally be divided into three types:

First type is for journal development and performance analysis. Many experts used this method providing scientific output evaluations and journal performances. For example, Wang conducted a survey of the journal: Eurasia Journal of Mathematics, Science and Technology Education using outputs from 2012 to 2017, presented its development and some suggestions for journal development (Wang et al., 2018). Journal: Remote Sensing was summarized of all published articles through the journal productions, knowledge units, keywords co-occurrence (Zhang et al., 2019). Merigó analyzed the Journal of Business Research between 1973 and 2014 (Merigo et al., 2016). By using the bibliometric, Modak et al. (2019) identified the leading trends in all Transportation Researches series journals in terms of impact, topics, authors, universities, and countries in its 50 years publications. Du and Teixeira (2012) took Chinese Economic Review literature as the econometric research object, and used this method to archived and analyzed the current situation and development trend of its publication. Australian Educational Researcher journal have been studied by Bates (Bates, 2003). Chen, Geng, and Zhu (2018) downloaded the published articles meta data from 2006 to 2015 in Agricultural Economic Review, and analyzed the development trend of China's Agricultural economy with this method. After 25 years' publishing history, Technological and Economic Development of Economy (TEDE) journal released a paper on its development history (Yu et al., 2019b), where 569 TEDE publications were analyzed from annual, geographical distributions, leading contributors including countries/territories, institutions, and authors. The journal Production Planning \& Control had been also conducted the knowledge landscape by Adeel in 2018 in which a comprehensive evaluations was conducted (Akmal et al., 2018). Deeper analysis can 
reveal research collaborations between organisations (Van Raan, 2005), authors, or countries, and evolution of the subjects within a selected field of knowledge (Viebahn \& Chappin, 2018; Zhang \& Zhou, 2019). Generally, the academic evaluation of a journal starts with judging its impact factor or ranking in its own fields, which can often significantly influence decisions about submission of manuscripts to a particular research publication (Tijssen \& Van Raan, 1994). The deeper analysis by bibliometric can provide forthcoming author a comprehensive understanding for the publication (Akmal et al., 2018). There are many different journals released its bibliometric analysis, not only including science and engineering journals, but also social science journals. Interestingly, almost all the above works were published in the journal that was the research target.

The second type of articles is focusing on a specific knowledge field. For example, Wei summarized output performances from top 5 economics journals, in which cross journals data are collected and ran in bibliometric environment (Wei, 2019). Merigo made collections on hot topics in business and economics researches, in which all papers were cross journals data collection and analysis based on the bibliometric, including one paper published on JBEM 2016 (Merigo et al., 2016). Zhang and Zhou (2019) collected 1120 papers studying the water foot print, made a summary for its research hot topics. Industrial Symbiosis is a keyword and field that had been evaluated systematically (Akhtar et al., 2019).

The last type of articles is review articles that mined the text and visualization in knowledge discovery. It usually provides the global trends and future forecasting in different disciplinary. This method has its great advantages in scientific research. It provided new ways to have new output visualization better than before. There are so many papers within this topic. Yu et al. (2019a) presented the coal research review published on Journal of Cleaner Production, gave us a new perspective in review article. Yu used the method in a section in his paper (Yu et al., 2017, 2018). Garrigos-Simon and Liu summarized the global trend of human capital development researches from bibliometric and visualization analysis methods after the statistics of research literature on human capital published the relevant research results in the Sustainability journal (Garrigos-Simon et al., 2018; Liu, 2017a, 2017b). Olczyk's paper published on the JBEM also witnessed the broad application using bibliometric (Olczyk, 2016), where he summarized the concept of International Competitiveness.

After surveys and observations, it is essential to have a retrospective review of the JEBM based on the articles published and available in Web of Science (WOS). We conduct such a comprehensive bibliometric profile that will help answer questions like:

1) What are the journal impact factors, total cites, their knowledge sources, and their influential fields?

2) Who are the most productive authors, the prolific institution, and the leading countries?

3) What are the main research themes and their changes of the JEBM in the past several years?

4) What are the citation impact of co-occurrences keywords of the JEBM? What does it mean for potential submitting paper?

Lastly, we hope to explore the research status of JBEM by bibliometric analysis, through which some meaningful information will be provided to improve the deep understanding of 
published articles. Therefore, in this study, we will draw a bibliometric retrospective knowledge landscape. The content in this paper would like to contribute and enrich the knowledge communication in business and economics. The text mining technology is one of the popular techniques in summarizing bibliographies, which could be informative and insightful for readers and forthcoming contributors.

The article was divided into 4 sections, which were Introduction, Materials and Methods, Results and Discussions as well as Conclusions, respectively. The study firstly explained what bibliometric analysis is and why we conduct a bibliometric analysis on JBEM in the Introduction section. In the next section, Materials and Methods, the process of the collecting data and what tools and software we adopted were elaborated. As for the section of Results and Discussions, the data collected were analyzed from three aspects: Dynamics and Trends of Publications, Productive and Influential Contributors, Thematic and Hot topic changes, which provided a comprehensive analysis to JBEM from different angles. At the last section, the main findings, limitations and future research possibilities were provided.

\section{Materials and methods}

\subsection{Data collection}

Founded by the American Institute for Science Information (ISI), SSCI (Social Sciences Citation Index) is a world-renowned Citation database of scientific and technological literature in the field of humanities and Social Sciences, including more than 3,300 high-quality academic journals in more than 50 research fields, including politics, economy, law, education, psychology, geography and history. It is an important tool for researchers to engage in social science research. It provides great convenience for researchers in the social science field to engage in academic research, institution cooperation establishing and new knowledge discovery. The SSCI database is also commonly used for bibliometric analysis (Ho, 2014).

This paper takes Social Science Citation Index (SSCI) in Web of Science" (WOS) core collections as the data sources to retrieve and download papers meta data. We took Journal of Business Economics and Management as publication name field to conduct searches. In total 683 records from 2007 to 2019 were downloaded in WOS for further analysis. The downloaded information included authors, title, publication year, page numbers, contact address, author keywords, keywords plus, countries/territories, institutions, journals, abstract, country, citations, and Web of Science categories. The SSCI database collected JBEM publications from 2007 till now. These publications document type distribute as articles (662), reviews (8), book reviews (5), correction (6), editorial materials (1) and retraction (1). In this study, only articles (662) and reviews (8) are used as the data sources for analysis.

\subsection{Glossary and methods description}

As mentioned above, a total of 683 JBEM publications were found in the SSCI database over the last decades. This section provides a detailed analysis of all the JBEM publications yearly or periodically. Various kinds of indicators are designed to describe the characteristics of these publications and their representative meanings are defined as follows: 
TP: Total publication number: article or review, exclude other document type in web of science.

TC: Total citations, total number of citations to all papers.

NA: Number of Authors.

TCR: Total Cited References.

ANA: Average number of authors per paper, ANA = NA/TP.

AP: Average paper length of published articles.

0C: The number of papers with "0" citation.

H-index: The h-index was proposed in 2005 by Hirsch (Hirsch, 2005). The h-index of a scientist means that $h$ articles in the published $N_{p}$ papers are cited at least $h$ times, while the rest of the $\mathrm{N}_{\mathrm{p}}$-h papers are cited less than or equal to $h$ times. The h-index not only reflects the frequency that a journal is cited, but also reflects the value and quality of the journal in a certain period of time. Unlike evaluating individual achievement, the journal's h-index is not about "life-time contribution", but the most common case is a single year, using in different situation.

There are many powerful tools or software for knowledge discovery, knowledge visualization, text mining, including Citespace, VOSViewer (van Eck \& Waltman, 2010; Waltman et al., 2010), Histcite, Bibcomb, pajak... These tools used common meta in papers: title, author, keywords, affiliation, references, grants to disclose the connecting network underline the text. By visualization technology, it adopted co-citation, co-occurrence, co-authorship, citations, bibliographic coupling to create maps connecting countries, organizations, institutions. This is an energetic research field.

\section{Results and discussions}

\subsection{Dynamics and trends of publications}

Among all these 670 publications, there are 1373 authors in total, 31016 cited references, and 1706 keywords.

\subsubsection{Annual publications and trends}

The data in the following Table 1 was collected and calculated through the electronic sheet. We introduce the indicator " $0 C$ " to reflect the published articles impact in scientific communication. We did not take the recent 3 years value into account as the recent 3 years " 0 " citation paper number does not represent the influential count of citation. The newer publication published, the less citation it receives in WOS system (Seltzer, 2018).

Table 1 presents the publishing profile of the JBEM from 2007 to 2019. As shown in the table, the trend of total publication number (TP) tended to be fluctuated, it initially increased gradually from 2007-2013, after TP reached the peak in 2013, and it experienced a sharp fluctuation and ultimately leveled up this year. During 2007-2008, total citations (TC) soared from 220 to 816 and basically kept steady until 2010, however, it witnessed a downward trend since then. As for total cited references (TCR) and average cited references (ACR), it seemed that the trend of TCR was fluctuated from 2007 to 2019 but it actually changed mainly with the change of total publication number; Nevertheless, ACR 
Table 1. Publishing profile of the JBEM

\begin{tabular}{|c|c|c|c|c|c|c|c|c|c|c|}
\hline Year & TP & TC & TCR & ACR & NA & $\begin{array}{c}\text { ANA } \\
(\text { NA/TP })\end{array}$ & ATC & h & AP & 0C \\
\hline 2007 & 31 & 220 & 574 & 18.52 & 58 & 1.87 & 7.1 & 10 & 8.8 & 0 \\
\hline 2008 & 34 & 816 & 1009 & 29.68 & 63 & 1.85 & 24 & 17 & 8.8 & 0 \\
\hline 2009 & 33 & 592 & 1206 & 36.55 & 66 & 2 & 17.94 & 15 & 11 & 0 \\
\hline 2010 & 34 & 708 & 2040 & 60 & 83 & 2.44 & 20.82 & 14 & 20.7 & 0 \\
\hline 2011 & 33 & 421 & 1862 & 56.42 & 82 & 2.48 & 12.76 & 11 & 20.6 & 0 \\
\hline 2012 & 51 & 422 & 2792 & 54.75 & 123 & 2.41 & 8.27 & 12 & 19.6 & 3 \\
\hline 2013 & 79 & 401 & 3945 & 49.94 & 193 & 2.44 & 5.08 & 9 & 18.7 & 13 \\
\hline 2014 & 57 & 334 & 2485 & 43.6 & 146 & 2.56 & 5.86 & 10 & 18.9 & 9 \\
\hline 2015 & 67 & 348 & 2908 & 43.4 & 169 & 2.52 & 5.19 & 9 & 18.4 & 7 \\
\hline 2016 & 78 & 351 & 3210 & 41.15 & 215 & 2.76 & 4.5 & 7 & 16.6 & 20 \\
\hline 2017 & 67 & 172 & 3288 & 49.07 & 204 & 3.04 & 2.57 & 6 & 18.6 & N/A \\
\hline 2018 & 44 & 38 & 2201 & 50.02 & 145 & 3.3 & 0.86 & 3 & 19 & N/A \\
\hline 2019 & 62 & 30 & 3496 & 56.39 & 186 & 3 & 0.48 & 3 & 20.6 & N/A \\
\hline Total & 670 & 4853 & 31016 & 46.29 & 1373 & 2.05 & 7.24 & N/A & N/A & N/A \\
\hline
\end{tabular}

Note: Indicators in the table: TP - Total publication number; TC - Total Citation number; TCR - Total cited references; ACR - Average cited references ACR = TCR/TP. NA - Number of authors. ANA Average number of authors per paper ANA = NA/TP; ATC - Average citation number ATC = TC/TP; AP - Average paper length of published articles.

showed an upward trend between 2007 and 2019, since the prevalence and popularization of the internet, scholars are more easily to get access to online publications, as the result, the number of average cited references all were approximately 50 in recent years, which was much higher than a decade ago. In addition, there were two indexes about author, which were number of authors (NA) and average number of authors per paper (ANA) respectively. NA was similar to the trend of TP and ANA that increased steadily in past 13 years, which demonstrated that authors prefer to work with more other authors compared with past. In term of h-index, the trend of them were consistent. They both reached the highest point in 2008, which were 24 and 17 respectively and both reached the lowest point in 2019, which were 0.48 and 3 respectively. There was a significant gap between the highest and lowest. At the last column, we collected the number of papers with " 0 " citation for publishing reference, the older the publication, the less " 0 " citation. In recent 3 years, we did not collect the indicator, in which reason lies in the newer publication, the more "0" citation.

Figure 1 shows the dynamics and trends of the annual publications of the JBEM and its yearly citations. In general, the number of publications published from 2007 to 2013 increased gradually, and the number of publications published from 2014 to 2016 was the second increasing trend, while the number of publications published from 2017 to 2019 (2019 data is uncompleted) decreased gradually. From the number of publications from 2007 to 2019. It is worth noting that the number of publications has peaked in 2013 (79 publications) 
and 2016 (78 publications). From 2007 to 2011, the number of publications was relatively stable, almost 30 per year. In 2016, 78 publications are published; in 2017, 67 publications are published, and in 2018, 44 publications are published, the number of publications decreased year by year. It is expected that it might publish around 50 papers per year. The citation line shows that it reached peak in 2008, then keep relatively stable around 350 per year.

There is a highly connections between 0 citation papers and the highest citation received time. In early years from 2007-2011, all papers had been cited, therefore the indicator of $O C$ had been 0 . The highest total citations received yearly was in 2008 reaching to be 816 , following decreasing in the thereafter years. The ATC means that each paper published on JBEM had received 7.24 times citations. This is a very important indicator for forthcoming authors who is expecting to have expected citation times.

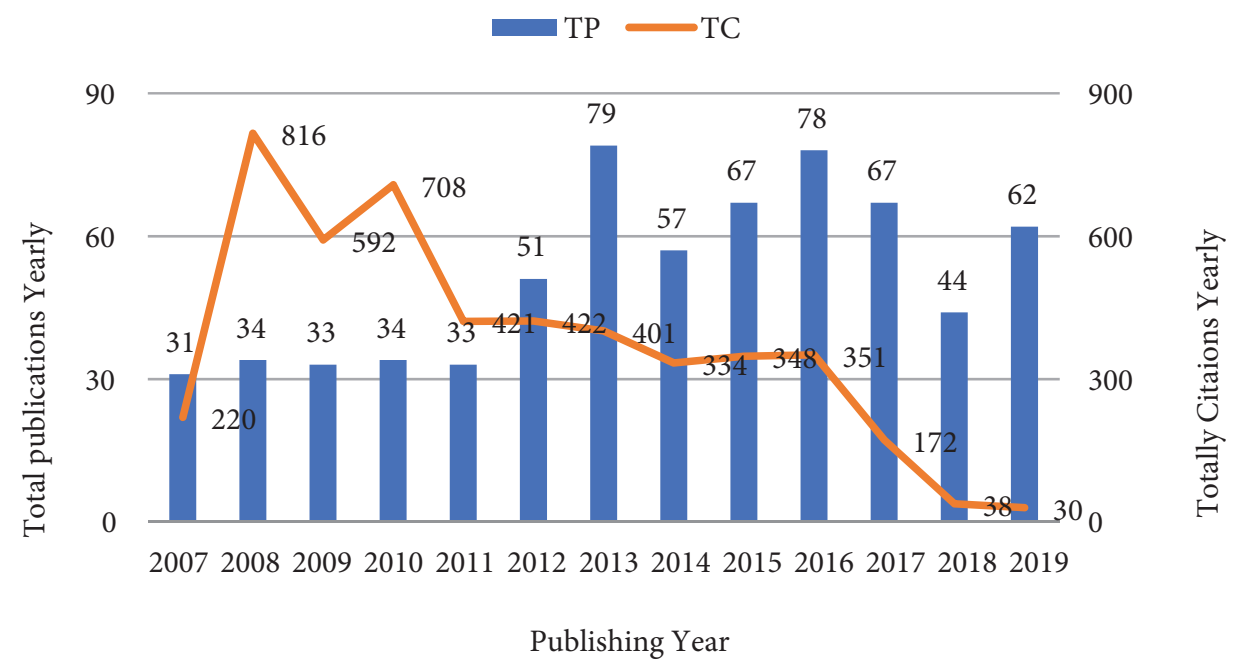

Figure 1. Trend of Total publications and Total Citations 2007-2019

\subsubsection{Knowledge flows}

JBEM itself is an important academic economic and business research publication that received great knowledge generation and dissemination. The following Figure 2 is the reference networks. The right side shows the journals that cited JBEM as references indexed by the Web of Science database. This reflects the knowledge flow from JBEM to other journals. We can see that the top 15 most representative journals. The journal list on the left side cited by publications in JBEM represents the knowledge source for papers in JBEM. The JBEM articles cited from all major journals are prominent by important publications: Strategic Management Journal, Journal of Finance, Journal of Marketing etc. It is generally argued that the self-citation rate of a mature journal should not be greater than 20\% (Zhang et al., 2019). The current self-citation rate on JBEM is highly correlated. As a result, there is a need for the articles submitted to JBEM to slightly increase citation from other best journals and slightly decrease citation from JBEM to reduce the self-citation rate. 

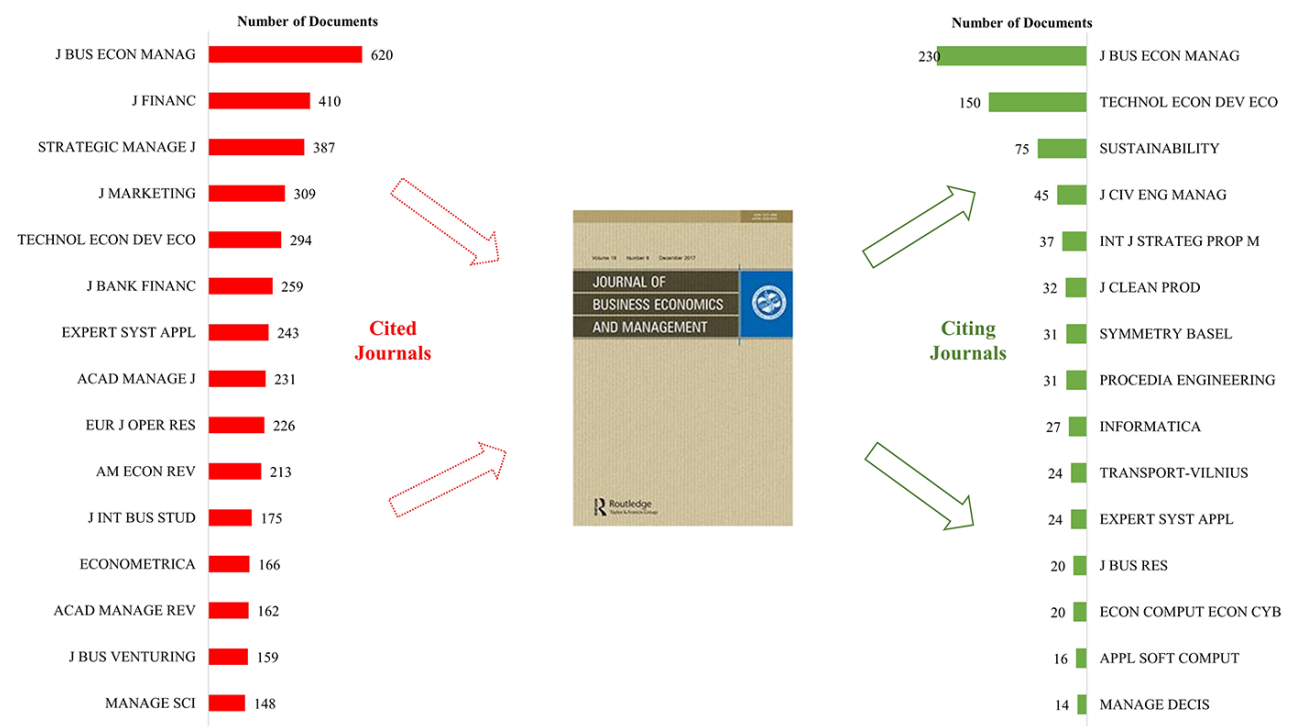

Figure 2. Knowledge Flow between JBEM and other sources

Figure 2 demonstrates the knowledge communication between JBEM and other publications. The knowledge flow on the left side of the figure is the knowledge origin where top 15 representative journals exerting to JBEM, which shows the number of citable items that JBEM cited from these 15 journals. These top 15 journals were innovation source and idea origin. Similarly, the knowledge flow on the right hand side of the figure is the top 15 journals that are influenced by JBEM, which illustrates the number of citable items cited from JBEM. It shows the knowledge mobilization directions among economics researches. Apparently, JBEM ranks the first at both the right and left hand. This reflects that JBEM itself is the most competitive journal or sister journal: "from and to". It is suggested that all the new contributor or author should have a retrospective search on the published articles in JBEM, seeking similar articles. So that it might fit the knowledge mainstreams.

The knowledge flow to and from JBEM is also shown in Figure 3 and Figure 4. In Figure 3 , the size of the node represents the number of cited times by JBEM. As can be seen in Figure 3, the main journals connecting each other is JBEM itself. The Journal of Finance, Strategic Management Journal, Journal of Marketing and Journal of Financial Economics which were cited by JBEM more than 300 times.

The colors of the nodes in Figure 3 and 4 represents the discipline to which the journal belonged to and the same color indicates that journals belong to the same discipline. It is easy to see from Figure 3, that there are five clusters, in which the purple nodes represent the clustered journals belong to general economic management, the blue clustered nodes represent the journals belong to operation and decision-making, management science, the yellow clustered nodes represent the journals belong to marketing, the green clustered nodes represent the journals belong to enterprise management and strategic management, while the 
clustered red nodes represent the journals on company finance studies. These 5 disciplines are typically mainstream in Economics and Management Science.

Similarly, Figure 4 demonstrates the status of publications in JBEM cited by other journals from 2007 through 2019, interpreting as knowledge sources for other journals and other publications. It is easy to observe that the JBEM itself win the first place, followed by Technological and Economic Development of Economy, Inzinerine Ekonomika-Engineering Economics, Transformations in Business \& Economics and Sustainability. The colors of the nodes in Figure 4 also represent the discipline to which the journal belongs to and the same color indicates that journals belong to the same discipline. All journal names showed here are sister journals within the same field clusters which will be proved again by keywords cooccurrence analysis.

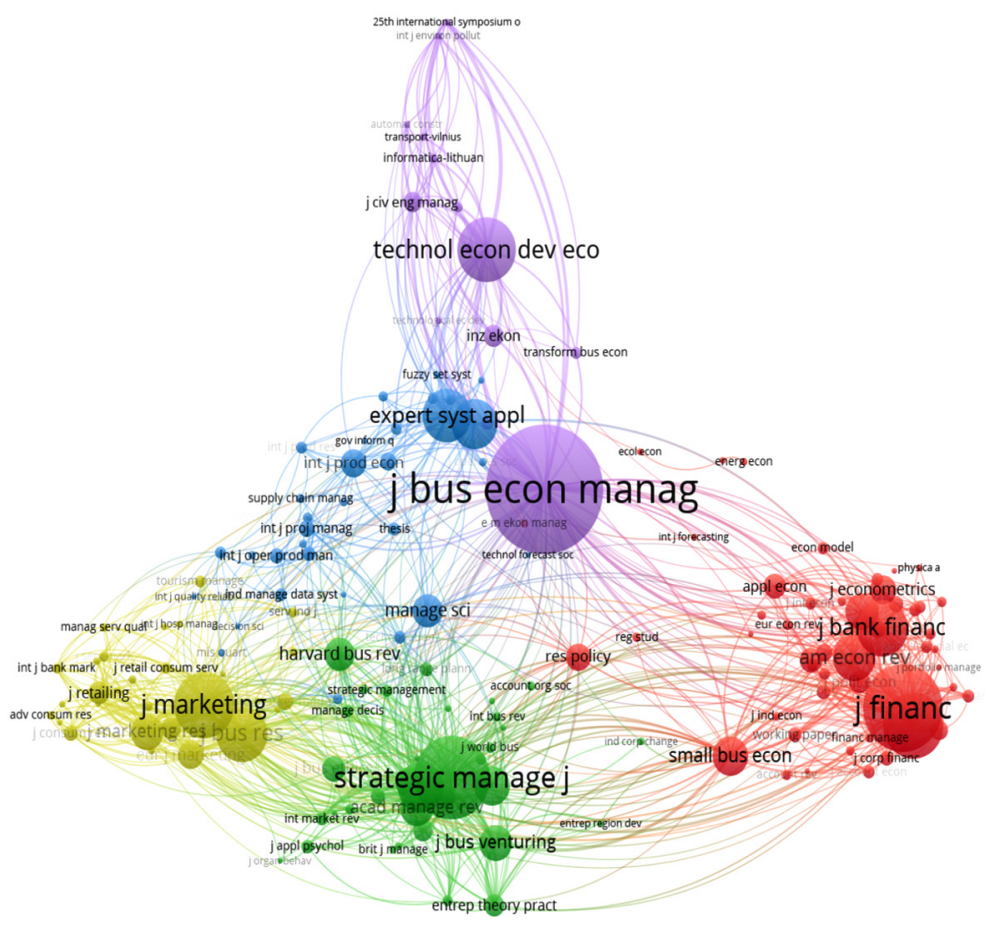

Figure 3. The Journals that are cited by JBEM

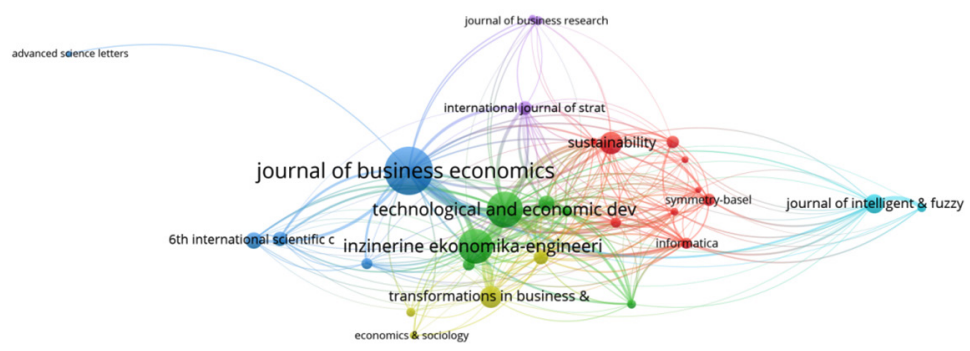

Figure 4. The map of citing publication of the JBEM 
Figure 3 and 4 present the knowledge or information structure of JBEM. All the important literature are connected through these nexus. If you are the forthcoming author, new papers with reference structure like current structures will be more likely be accepted. Good paper should have a broad review on the published similar publication in these knowledge structure, then bring new ideas or innovations to JBEM. If the new papers references have less likely reference structure, it might not have been in scope of the JBEM.

\subsection{Productive and influential contributors}

\subsubsection{Leading authors and knowledge sources}

By the year of 2019, the JBEM includes publications from 1373 authors. Among these authors, 1,074 authors only published one article, 119 authors published two articles for each author, 39 authors published three articles for each author and 29 authors published more than three articles for each author. Table 2 displays the most productive authors of the JBEM with publications $(>5)$. As can be seen from Table 2, the most productive author is Zavadskas E. K. ( $n=20,3.19 \%)$ from Vilnius Gediminas Technical University, followed by Ginevicius R. (Editor-in-Chief of JBEM, $n=16,2.55 \%)$, Tvaronaviciene M. ( $\mathrm{n}=12,1.91 \%)$, Turskis Z. $(\mathrm{n}=8,1.27 \%)$ and Ferreira F. A. F. $(\mathrm{n}=16,2.55 \%)$ from University Institute of Lisbon and The University of Memphis.

Interestingly, 10 of the top 14 authors in terms of number of articles published in Journal of Business Economics and Management (JBEM) were from this Vilnius Gediminas Technical University which is the sponsor of the journal. This indicates that the journal has become an important way to publicize the disseminating management ideas of Vilnius Gediminas Technical University. For further study, we also employ h-index to evaluate the top 14 authors' performances, the results indicate that Zavadskas E. K., Ginevicius R. and Tvaronaviciene M., all three are from Vilnius Gediminas Technical University, not only are the authors in the top three for the number of articles published, but they also win the top three places in the $\mathrm{h}$-index. This indicator shows that they contribute great new ideas and discoveries to business fields.

Among all the publication, Wei guiwu was enlisted as highly cited paper in Essential Science Indicators (ESI) database since May 10, 2019 (Wei, 2016). A Highly Cited Paper is a paper that received citations in the top $1 \%$ of the academic field of economic and business based on a highly cited threshold for the field and publications. This one is effective as of May 9 till July 10, 2019, when ESI updated on May 9, 2019, covering a 10 year and 2 months period, January 1, 2009 - February 28, 2019. This is the first bi-monthly update of 2019. Furthermore, Wei Guiwu had been identified as Highly Cited Researcher list released by Clarivate Analystics in 2015, 2016, 2017. This paper had received 103 citations since 2016 (Wei, 2016). This indicator shows that the highly recognized scholar bring better contribution to journal development.

The top 10 most cited papers in all the publications are also deserve further discussion. They proved that the founder of the JBEM had made great contributions and influential knowledge in the business and economics fields. Most of these highly cited papers published during 2008-2010, it implies that the published original innovations papers need 10 years reaching its 
Table 2. Most productive authors of the JBEM with publications $(>5)$

\begin{tabular}{|c|c|c|c|c|c|c|c|}
\hline Rank & Author & Institutions & $\begin{array}{l}\text { Number } \\
\text { of Publi- } \\
\text { cations }\end{array}$ & $\begin{array}{l}\text { Total } \\
\text { Cita- } \\
\text { tions }\end{array}$ & $\begin{array}{c}\text { Total } \\
\text { Citations/ } \\
\text { Publications }\end{array}$ & $\begin{array}{l}\text { Percen- } \\
\text { tage/628 }\end{array}$ & $\mathrm{H}$-index \\
\hline 1 & Zavadskas E. K. & $\begin{array}{l}\text { Vilnius Gediminas } \\
\text { Tech Univ }\end{array}$ & 20 & 735 & 36.75 & 3.19 & 14 \\
\hline 2 & Ginevicius R. & $\begin{array}{l}\text { Vilnius Gediminas } \\
\text { Tech Univ }\end{array}$ & 16 & 454 & 28.38 & 2.55 & 11 \\
\hline 3 & $\begin{array}{l}\text { Tvaronavi- } \\
\text { ciene M. }\end{array}$ & $\begin{array}{l}\text { Vilnius Gediminas } \\
\text { Tech Univ }\end{array}$ & 12 & 275 & 22.92 & 1.91 & 10 \\
\hline 4 & Turskis Z. & $\begin{array}{l}\text { Vilnius Gediminas } \\
\text { Tech Univ }\end{array}$ & 8 & 439 & 54.88 & 1.27 & 7 \\
\hline 5 & Ferreira F. A. F. & $\begin{array}{l}\text { Univ Inst Lisbon/ } \\
\text { Univ Memphis }\end{array}$ & 7 & 70 & 10 & 1.12 & 5 \\
\hline 6 & Korsakiene R. & $\begin{array}{l}\text { Vilnius Gediminas } \\
\text { Tech Univ }\end{array}$ & 7 & 85 & 12.14 & 1.12 & 4 \\
\hline 7 & Peleckis K. & $\begin{array}{l}\text { Vilnius Gediminas } \\
\text { Tech Univ }\end{array}$ & 7 & 30 & 4.29 & 1.12 & 4 \\
\hline 8 & Alas R. & $\begin{array}{l}\text { Estonian Business } \\
\text { Sch }\end{array}$ & 6 & 68 & 11.33 & 0.96 & 5 \\
\hline 9 & Skare M. & $\begin{array}{l}\text { Juraj Dobrila Univ } \\
\text { Pula }\end{array}$ & 6 & 8 & 1.33 & 0.96 & 2 \\
\hline 10 & Mardani A. & $\begin{array}{l}\text { Univ Teknol } \\
\text { Malaysia }\end{array}$ & 5 & 53 & 10.6 & 0.80 & 2 \\
\hline 11 & $\begin{array}{l}\text { Rutkaus- } \\
\text { kas A. V. }\end{array}$ & $\begin{array}{l}\text { Vilnius Gediminas } \\
\text { Tech Univ }\end{array}$ & 5 & 33 & 6.6 & 0.80 & 4 \\
\hline 12 & Smaliukiene R. & $\begin{array}{l}\text { Vilnius Gediminas } \\
\text { Tech Univ/ Gen } \\
\text { Jonas Zemaitis Mil } \\
\text { Acad Lithuania }\end{array}$ & 5 & 40 & 8 & 0.80 & 4 \\
\hline 13 & Stankeviciene J. & $\begin{array}{l}\text { Vilnius Gediminas } \\
\text { Tech Univ }\end{array}$ & 5 & 29 & 5.8 & 0.80 & 3 \\
\hline 14 & Streimikiene D. & $\begin{array}{l}\text { Vilnius Univ/ } \\
\text { Lithuanian Inst } \\
\text { Agr Econ }\end{array}$ & 5 & 17 & 3.4 & 0.80 & 2 \\
\hline
\end{tabular}

peak citations. These 8 papers were from management sciences, which the keywords including AHP, SWOT methodology, TOPSIS, competitiveness, were all important methodology. 8 of the 10 articles are from Lithuanian authors who were working at Vilnius Gediminas Technical University. As it is a Lithuanian university and publisher of JBEM, it is necessary to conduct the citation analysis of the eight most cited Lithuanian articles, which is of great reference value for the academic research of JBEM, Vilnius Gediminas Technical University and even Lithuania authors. We had further studied the citations that had cited these 8 papers.

The citations represented by these 8 papers give us some clues in knowledge discovery. It can be analyzed from 4 aspects: the top 10 journals/conferences, institutions, countries 
and the 10 most frequent keywords of articles that cited these 8 articles. The scopes of the 10 journals/conferences are economics, management, sustainability, civil management, and transportation. Among them, Technical and Economic Development of Economy, Journal of Business Economics and Management, Journal of Civil Engineering and Management, Transport and International Journal of Strategic Property Management are published by Vilnius Gediminas Technical University; Inzinerine Ekonomika-Engineering Economics and Transformations in Business \& Economics are the journals published by other Lithuanian Universities; the only conference was also held in 2010 in Vilnius, the capital of Lithuania. It can be referred that most of the citations to these eight articles come from Lithuania, especially Vilnius Gediminas Technical University, which also corresponds to the institutions and countries in the latter two columns (Supplementary material, Table A2). The most cited institutions and countries are Vilnius Gediminas Technical University and Lithuania, respectively, which far exceed other countries and institutions. But the influence of these eight articles is not only within the Lithuanian countries, it also demonstrates that these articles have also been cited by Iran, Serbia, China, Turkey, Poland, the Czech Republic and Malaysia, which to some extent that they have certain influence in Eastern Europe and Asia. As for the top ten keywords in the articles citing these eight articles, we can also find that these ten keywords are some of the fields, methods, and hot words in the previously mentioned fields, among which multiple-criteria decision analysis is the most adopted methods.

\subsubsection{Leading institutions}

From the section 2.2.1, the leading productive authors, we know, among 14 authors, 10 were from Vilnius Gediminas Technical University. This university played important role and ranked as top university in Business and Economics. The newly updated ESI data proved that it is ranked as 294 of total 333 top 1\% organizations. In addition, there are many other renowned institutions contributed to JBEM, in this section, the 15 Most productive institutions in the JBEM was discussed in detail.

The data shows the top 15 most productive institutions, with the number of publications being greater than 5 . Vilnius Gediminas Technical University $(\mathrm{n}=125,19.90 \%)$ ranks first in the number of publications, followed by Kaunas University of Technology ( $\mathrm{n}=15,2.39 \%)$, University of Ljubljana ( $\mathrm{n}=15,2.39 \%)$, Tomas Bata University Zlin $(\mathrm{n}=10,1.59 \%)$, University of Economics Prague( $\mathrm{n}=10,1.59 \%)$, University of Maribor $(\mathrm{n}=10,1.59 \%)$, University of Zaragoza $(n=10,1.59 \%)$, Universiti Kebangsaan Malaysia $(n=9,1.43 \%)$, Eastern Mediterranean University $(\mathrm{n}=7,1.12 \%)$, Islamic Azad University $(\mathrm{n}=7,1.12 \%)$, Universidade Da Beira Interior $(n=7,1.12 \%)$, and Universidade De Lisboa $(n=7,1.12 \%)$. As for the average citation, Vilnius Gediminas Technical University (16.14, Lithuania) has the highest average citation frequency. It was followed by Islamic Azad University (15.57, Iran), Estonian Business School (12.60, Estonia), Eastern Mediterranean University (12.14, The Czech Republic), University of Economics Prague (11.4, The Czech Republic), City University of Hong Kong (10.6, China) and Universiti Kebangsaan Malaysia (10.11, Malaysia). Interestingly, among these 15 institutions, only one of the 15 most productive institutions is from North America (University of Memphis, USA), three of them are from Asia (Universiti Kebangsaan Malaysia, Malaysia; Islamic Azad University, Iran; Universiti Putra Malaysia, Malaysia), and the rest are 
from Europe. So, in the JBEM, European institutions account for the largest proportion and the contribution from Asia universities is becoming increasingly important to some extent, it can reflect the degree of JBEM's impact on these areas. Besides, among all the institution, except for Tomas Bata University Zlin and University of Economics Prague, the rest all are enlisted as top 1\% universities in ESI database (as of September 11, 2019), which further manifest the research quality of these institution.

\subsubsection{Leading countries/territories}

Until the year 2019, a total of 66 countries (territories) and 577 institutions have published their articles in the Journal of Business Economics and Management (JBEM). Table 3 displayed the most productive countries (territories) which have been published more than 10 articles. The most productive country (territories) is Lithuania $(\mathrm{n}=156,24.84 \%)$ which is also the registered country of the publication. Followed by Spain $(\mathrm{n}=69,10.99 \%)$, USA $(\mathrm{n}=47,7.48 \%)$, Turkey $(\mathrm{n}=46,7.33 \%)$, Peoples R China $(\mathrm{n}=39,6.21 \%)$, Taiwan $(\mathrm{n}=38$, $6.05 \%)$, Czech Republic $(\mathrm{n}=34,5.41 \%)$, Malaysia $(\mathrm{n}=34,5.41 \%)$ and have published more than 30 of the publications. Table 3 also displays the total citations of the most productive countries (territories), which points out that Lithuania $(n=2,187)$, Iran $(n=359)$, Turkey $(\mathrm{n}=332)$, USA $(\mathrm{n}=328)$ and Peoples R China $(\mathrm{n}=311)$ are noteworthy high influence

Table 3. Most productive countries (territories) of Journal of Business Economics and Management (JBEM) publications $(>10)$

\begin{tabular}{|c|l|c|c|c|c|c|}
\hline Rank & Country & $\begin{array}{c}\text { Number of } \\
\text { Publications }\end{array}$ & $\begin{array}{c}\text { Total } \\
\text { Citations }\end{array}$ & $\begin{array}{c}\text { Total Citations/ } \\
\text { Publications }\end{array}$ & Percentage/628 & H-index \\
\hline 1 & Lithuania & 156 & 2,187 & 14.02 & 24.84 & 25 \\
\hline 2 & Spain & 69 & 297 & 4.3 & 10.99 & 9 \\
\hline 3 & USA & 47 & 328 & 6.98 & 7.48 & 11 \\
\hline 4 & Turkey & 46 & 332 & 7.22 & 7.33 & 11 \\
\hline 5 & $\begin{array}{l}\text { Peoples R } \\
\text { China }\end{array}$ & 39 & 311 & 7.97 & 6.21 & 9 \\
\hline 6 & Taiwan & 38 & 121 & 3.18 & 6.05 & 7 \\
\hline 7 & $\begin{array}{l}\text { Czech } \\
\text { Republic }\end{array}$ & 34 & 203 & 5.97 & 5.41 & 9 \\
\hline 8 & Malaysia & 34 & 281 & 8.26 & 5.41 & 9 \\
\hline 9 & Portugal & 29 & 159 & 5.48 & 4.62 & 7 \\
\hline 10 & Slovenia & 27 & 173 & 6.41 & 4.30 & 7 \\
\hline 11 & Poland & 26 & 132 & 5.08 & 4.14 & 8 \\
\hline 12 & Iran & 25 & 359 & 14.36 & 3.98 & 11 \\
\hline 13 & England & 21 & 137 & 6.52 & 3.34 & 7 \\
\hline 14 & Slovakia & 18 & 44 & 2.44 & 2.87 & 4 \\
\hline 15 & Italy & 13 & 59 & 4.54 & 2.07 & 5 \\
\hline
\end{tabular}


contributors to the journal. The h-index analysis of the most productive countries (territories) indicates that some countries (territories) perform well on h-index, such as Lithuania (h-index $=25)$, Iran (h-index $=11)$, USA (h-index $=11)$ and Turkey (h-index $=11)$. Also, after integrated the analysis results of number of publications, total citations, total citations/ publication and h-index analysis, we must highlight Lithuania is the best-performing country. Besides, it is interesting to note that Asian countries (territories) are not as good as European countries (territories) in terms of number of publications, the average citations number of Asian countries (territories) is at a relatively high level, for instance, the average citations number of China, Malaysia and Iran are all higher than 7, which even performed better than some countries (territories) with high scientific research level, such as the USA and England, this could manifest the progress of scientific research in Asia.

\subsection{Thematic and hot topic changes}

In the bibliometric, the co-occurrence of the keywords represents the publication topic changes. Keywords information about the core content of articles are listed. Therefore, keyword analysis can be used to identify evolving research frontiers relating to a knowledge domain (Silva \& Teixeira, 2011). Keywords can summarize the core meaning of the article and add richer interpretations to understanding the concentration of research themes since underlying concepts of an article. They were selected by authors and gives reader landmark and clue to capture its main topic. Therefore, keywords investigation of Journal of Business Economics and Management can add more explanations to help readers to understand the concentration of the journal. Based on its frequency of appearance, the keyword form can give us many interesting information.

The focus and hot topics in different stage always change with the time. In this section, we are going to survey the co-occurrence of keywords in different period, so as to identify the academic trends. In order to identify the topics changes over the periods of the JBEM publications, all 13 years from 2007-2019 can be divided into three different sub stages: 2007 2010, 2011 2014, and 2015 2019. In each part, the co-occurrence networks of each keyword can be compared separately and listed in forms. The most frequently used keyword is "performance" in the all three stage, which presents the whole economic and business research, while, the

Table 4. Keywords Change in three different stages

\begin{tabular}{|l|l|l|l|l|l|}
\hline $\begin{array}{c}\text { 2007-2010 } \\
\text { (Subset I) }\end{array}$ & $\begin{array}{c}\text { 2011-2014 } \\
\text { (Subset II) }\end{array}$ & $\begin{array}{c}\text { 2015-2019 } \\
\text { (Subset III) }\end{array}$ & \multicolumn{1}{|c|}{$\begin{array}{c}\text { Subset } \\
\text { I \& II }\end{array}$} & \multicolumn{1}{|c|}{$\begin{array}{c}\text { Subset } \\
\text { II \& III }\end{array}$} & \multicolumn{1}{|c|}{$\begin{array}{c}\text { Subset } \\
\text { I \& III }\end{array}$} \\
\hline Lithuania & volatility & information & behavior & productivity & market \\
\hline construction & environment & SMEs & decision-making & innovation & strategy \\
\hline FDI & investment & framework & selection & industry & \\
\hline $\begin{array}{l}\text { sustainable } \\
\text { development }\end{array}$ & $\begin{array}{l}\text { ownership } \\
\text { structure }\end{array}$ & perspective & & risk & \\
\hline China & & & & efficiency & \\
\hline alternatives & & & & & \\
\hline
\end{tabular}


"model" represent difference a key research method: mathematics modeling, econometric modeling, decision making model, so that it occurred in all three stages. This is to verify that as top journal and influential publication, JBEM had contributed intellectual structures.

There are some changes in the co-occurrence of keywords published in the JBEM in the past 13 years. Apparently, the keyword "Lithuania" in many papers during 2007-2010, however, it had been dropped out of the scope of authors in next two stages. This is to certificate that local economics problem had been replaced steadily by other international problems, which means the journal are accepting more new papers on other countries. Same topic including keywords: "China", "Construction", "FDI", "Sustainable Development", "Alternatives" have same situation. In subset II, keywords: "Volatility", "Environment", "Investment", "Ownership", "Structure" are key topics during 2011-2014. In recent 5 years, keywords," Information", "SMEs", "Framework", "Perspective" are new research topics and new trends with highly occurrence frequency.

Table 4 shows us some topics have crossed two subsets. For example, "behavior", "Decision Making" and "selection" are highly presented during 2007-2014, while "productivity", "Innovation", "Industry", "Risk" and "Efficiency" were hot topics during 2014-2019. Only two keywords, "market" and "strategy" are hot topic in subset I and subset III.

It deserves to notice that all the keywords presented here can be found in difference papers in its keywords or author plus keywords edited by experts in Web of Science editorial team. Moreover, content analysis of "frequency word count" was used to observe the impact of special issues on the development of increasing interest in a particular area (Akmal et al., 2018).

\subsection{Keywords comparison}

In this section, we have had a deep text mining and comparison between the JBEM and all Highly Cited Paper and Hot paper in Web of Science. The aims are to have a comprehensive understanding of all published articles. So that the reader will have a clue to choose their research directions, and make new contributions.

Highly cited papers \& Hot papers are current trends and mainstream in a particular field. We take the "business" and "economics" as the subject keywords and search in the Web of Science database. A total of 485 highly cited papers and 36 hot papers were selected for analysis. Then, we had received the highly frequent co-occurrence keywords that is listed in Table 5. Scholars focus on sustainability, big data, circular economy, corporate social responsibility, sustainable development, economics, business model, literature review, sharing economy.

According to the comparison, it can be seen that in recent years, the papers published by JBEM are very different form the keywords of highly cited papers and hot papers in the similar fields. JBEM pays more attention to general topics in the management field such as "management" and "performance", while highly cited papers and hot papers pay more attention to today's hot topics such as "sustainability" and "big data".

The keyword "performance" co-occurs in different text and research fields (Figure 5). Performance is highly associated with financial performance, firm performance, organizational performance, performance measurement. It is an ongoing research field, including firm, 
Table 5. Comparison of Key Words between JBEM and Hot Papers \& Highly Cited Papers

\begin{tabular}{|l|c|l|c|}
\hline \multicolumn{2}{|c|}{ JBEM 2015-2019 } & \multicolumn{2}{c|}{ Hot papers \& Highly cited papers 2017-2019 } \\
\hline Keywords & Frequency & \multicolumn{1}{c|}{ Keywords } & Frequency \\
\hline performance & 69 & sustainability & 22 \\
\hline impact & 33 & big data & 16 \\
\hline management & 32 & circular economy & 16 \\
\hline innovation & 32 & corporate social responsibility & 14 \\
\hline determinants & 31 & sustainable development & 13 \\
\hline risk & 18 & economics & 11 \\
\hline productivity & 17 & business model & 10 \\
\hline growth & 16 & literature review & 10 \\
\hline models & 15 & sharing economy & 10 \\
\hline firms & 15 & climate change & 9 \\
\hline information & 14 & supply chain management & 9 \\
\hline SMEs & 14 & big data analytics & 8 \\
\hline efficiency & 14 & cloud computing & 8 \\
\hline industry & 13 & innovation & 8 \\
\hline market & 13 & bibliometrics & 7 \\
\hline framework & 13 & business model innovation & 7 \\
\hline perspective & 11 & entrepreneurship & 7 \\
\hline strategy & 11 & firm performance & 7 \\
\hline
\end{tabular}

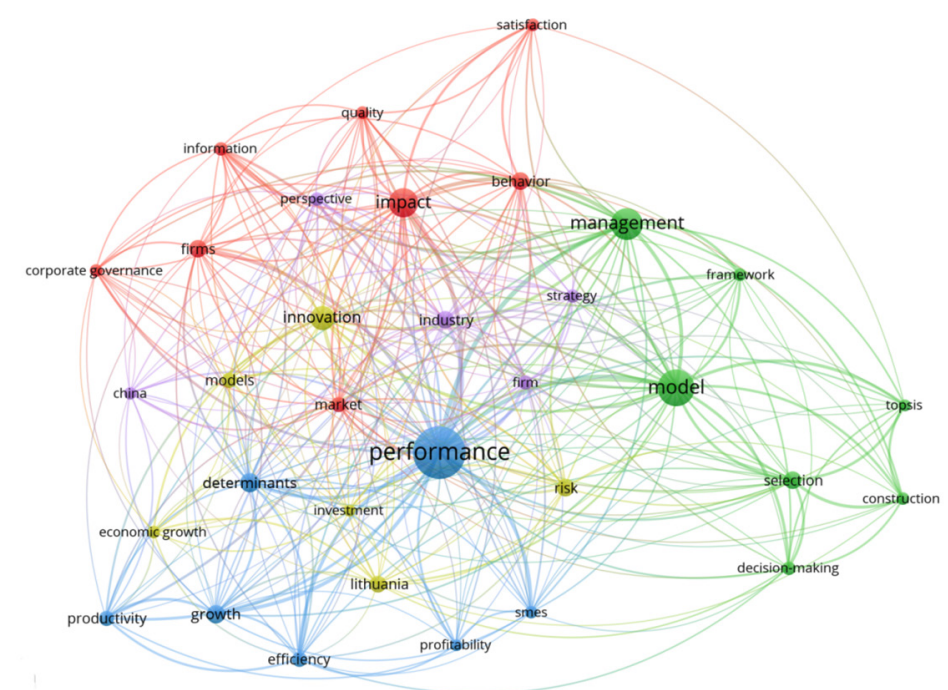

Figure 5. Keywords co-occurrence of papers 2007-2019 
SMEs, innovation, productivity. All the perspective researchers are highly recommended that previous performance research should be referred and evaluated.

\section{Conclusions}

This study presents a bibliometric analysis on all the indexed records from JBEM publications in the SSCI database. The basic characteristics of the JBEM journal, including annual publication trends, knowledge communications, the influential contributors as well as thematic topics change were studied in detail.

The results indicate that the number of papers published each year by the JBEM journal is relatively stable and is slightly reduced and published papers has an expected citation number of 7.68 times. The prestigious publications, such as UT 24 journals, consisted with the knowledge sources, and environment economics are becoming more popular than before in recent publications. Management science (decision-making), marketing, finance, firm governance, technological economics, econometrics are mainstreams in all publications. The keyword, "Performance" is the most frequent occurrence in all papers. Among the 10 most cited papers, eight articles have considerable influence in Lithuania, Asia, and Eastern Europe, and are also contributive for economics, management, civil engineering, sustainability and transportation research.

Among all the leading institutions or organizations, 3 universities from $1 \%$ top universities in ESI database contribute 137 papers, taking $21.8 \%$ of all records. One highly cited researcher brought 1 published paper with 103 citations. The authors of the JBEM journal are internationally distributed in Lithuania, Spain, USA, Turkey, China and other countries/ territories. The question of how to make more countries with influential scientific research strength pay attention to this journal is an important challenge in the future. In addition, the number of papers published since 2016 has decreased considerably, in that case, the question is how to maintain or improve the IF of this journal is another important challenge. It is suggested that more papers from highly cited researchers be published in this journal in order to improve their influence.

The difference in frequency of keywords in different stages give us informative clue for future studies. The topic of the journal has been changed with time. At the beginning, many papers are published centering the economic problems in Lithuania, then, more papers studying the theoretical problem were accepted in recent years. As the world economy is facing various pressures, such as transformation, economic growth, trade wars, the new trends represented by circular economy and share economy had received attentions in highly cited papers and hot papers. These are new trends deserved new submissions contributing their thoughts and discoveries.

There are also some limitations in the article, since we collected the data from Web of Science and this database is constantly updating, the analysis could just reflect the performance of JBEM at certain period. In addition, there are some aspects can be further analyzed, for example, keywords comparison could be further explored, future research should reflect more about the changes of keywords, which may have more practical significance. At the 
same time, this article is also useful for many scholars. This type of article can be applied to different journals to study the performance of them.

\section{Author contributions}

Xintu Lei and Qingyuan Xu conceived the study and were responsible for the design and development of the data analysis. Xintu Lei was responsible for data collection and analysis, as well as data interpretation. Qingyuan $\mathrm{Xu}$ was responsible for language check and wrote the first draft, revision of the article.

\section{Disclosure statement}

We declare that we do not have any competing financial, professional, or personal interests from other parties.

\section{References}

Akhtar, N., Saqib, Z., Khan, M. I., Martin, M. A., Atif, S. B., \& Zaman, M. H. (2019). A bibliometric analysis of contemporary research regarding industrial symbiosis: A path towards urban environmental resilience. Applied Ecology and Environmental Research, 17(1), 1159-1221. https://doi.org/10.15666/aeer/1701_11591221

Akmal, A., Podgorodnichenko, N., Greatbanks, R., \& Everett, A. M. (2018). Bibliometric analysis of production planning and control (1990-2016). Production Planning \& Control, 29(4), 333-351. https://doi.org/10.1080/09537287.2018.1429030

Aksnes, D. W., \& Sivertsen, G. (2004). The effect of highly cited papers on national citation indicators. Scientometrics, 59(2), 213-224. https://doi.org/10.1023/B:SCIE.0000018529.58334.eb

Andres, A. (2010). Measuring academic research: How to undertake a bibliometric study. Oxford Chandos Publishing.

Bates, R. (2003). Phelan's bibliometric analysis of the impact of Australian educational research. Australian Educational Researcher, 30(2), 57-64. https://doi.org/10.1007/BF03216790

Chen, Q. H., Geng, N., \& Zhu, K. (2018). Review and bibliometric analysis of Chinese agricultural economics research: 2006-2015. China Agricultural Economic Review, 10(1), 152-172. https://doi.org/10.1108/CAER-07-2017-0141

Du, Y. X., \& Teixeira, A. A. C. (2012). A bibliometric account of Chinese economics research through the lens of the China Economic Review. China Economic Review, 23(4), 743-762. https://doi.org/10.1016/j.chieco.2012.04.009

Garrigos-Simon, F. J., Botella-Carrubi, M. D., \& Gonzalez-Cruz, T. F. (2018). Social capital, human capital, and sustainability: A bibliometric and visualization analysis. Sustainability, 10(12). https://doi.org/10.3390/su10124751

Hirsch, J. E. (2005). An index to quantify an individual's scientific research output. Proceedings of the National Academy of Sciences of the United States of America, 102(46), 16569-16572. https://doi.org/10.1073/pnas.0507655102

Ho, Y. S. (2014). Classic articles on social work field in Social Science Citation Index: A bibliometric analysis. Scientometrics, 98(1), 137-155. https://doi.org/10.1007/s11192-013-1014-8 
Lei, X. T., \& Xu, Q. Y. (2020). Evolution and thematic changes of Journal of King Saud University - Science between 2009 and 2019: A bibliometric and visualized review. Journal of King Saud University - Science, 32(3), 2074-2080. https://doi.org/10.1016/j.jksus.2020.02.006

Liu, Z. L. (2017a). China's plans and policies for reducing $\mathrm{CO}_{2}$ emission from biomass-fired power plants: Modeling and economic study. Energy Sources Part B-Economics Planning and Policy, 12(11), 1001-1006. https://doi.org/10.1080/15567249.2017.1347727

Liu, Z. L. (2017b). China's strategy for the development of renewable energies. Energy Sources Part BEconomics Planning and Policy, 12(11), 971-975. https://doi.org/10.1080/15567249.2017.1336813

Merigo, J. M., Rocafort, A., \& Aznar-Alarcon, J. P. (2016). Bibliometric overview of business \& economics research. Journal of Business Economics and Management, 17(3), 397-413. https://doi.org/10.3846/16111699.2013.807868

Modak, N. M., Merigo, J. M., Weber, R., Manzor, F., \& Ortuzar, J. D. (2019). Fifty years of Transportation Research journals: A bibliometric overview. Transportation Research Part A: Policy and Practice, 120, 188-223. https://doi.org/10.1016/j.tra.2018.11.015

Olczyk, M. (2016). Bibliometric approach to tracking the concept of international competitiveness. Journal of Business Economics and Management, 17(6), 945-959. https://doi.org/10.3846/16111699.2016.1236035

Pranulis, V. (2004). Business education in Lithuania. Transformations in Business \& Economics, 3, 19-29.

Seltzer, A. J. (2018). Publication trends and future challenges for the Australian economic history review: A bibliometric analysis. Australian Economic History Review, 58(2), 112-133. https://doi.org/10.1111/aehr.12143

Silva, M. C. e, \& Teixeira, A. A. C. (2011). A bibliometric account of the evolution of EE in the last two decades: Is ecological economics (becoming) a post-normal science? Ecological Economics, 70(5), 849-862. https://doi.org/10.1016/j.ecolecon.2010.11.016

Statistics Lithuania. (2013). Structure of gross value added by production approach by economic activity. Economy and Finance. Official Statistics Portal. Retrieved November 24, 2019, from https://osp. stat.gov.lt/en/rodikliai38

Tijssen, R. J. W., \& Van Raan, A. F. J. (1994). Mapping changes in science and technology - bibliometric co-occurrence analysis of the R\&D literature. Evaluation Review, 18(1), 98-115. https://doi.org/10.1177/0193841X9401800110

van Eck, N. J., \& Waltman, L. (2010). Software survey: VOSviewer, a computer program for bibliometric mapping. Scientometrics, 84(2), 523-538. https://doi.org/10.1007/s11192-009-0146-3

Van Raan, A. F. J. (2005). Fatal attraction: Conceptual and methodological problems in the ranking of universities by bibliometric methods. Scientometrics, 62(1), 133-143. https://doi.org/10.1007/s11192-005-0008-6

Viebahn, P., \& Chappin, E. J. L. (2018). Scrutinising the gap between the expected and actual deployment of carbon capture and storage - a bibliometric analysis. Energies, 11(9), 45. https://doi.org/10.3390/en11092319

Waltman, L., van Eck, N. J., \& Noyons, E. C. M. (2010). A unified approach to mapping and clustering of bibliometric networks. Journal of Informetrics, 4(4), 629-635.

https://doi.org/10.1016/j.joi.2010.07.002

Wang, P., Zhu, F. W., Song, H. Y., \& Hou, J. H. (2018). A bibliometric retrospective of the journal Eurasia Journal of Mathematics, Science and Technology Education between 2012 and 2017. Eurasia Journal of Mathematics Science and Technology Education, 14(3), 765-775. https://doi.org/10.12973/ejmste/80911

Wei, G. W. (2016). Picture fuzzy cross-entropy for multiple attribute decision making problems. Journal of Business Economics and Management, 17(4), 491-502.

https://doi.org/10.3846/16111699.2016.1197147 
Wei, G. Y. (2019). A bibliometric analysis of the top five economics journals during 2012-2016. Journal of Economic Surveys, 33(1), 25-59. https://doi.org/10.1111/joes.12260

Yu, H., Wang, Y., Li, X., Wang, C., Sun, M., \& Du, A. (2019a). Measuring ecological capital: State of the art, trends, and challenges. Journal of Cleaner Production, 219, 833-845. https://doi.org/10.1016/j.jclepro.2019.02.014

Yu, D. J., Xu, Z. S., \& Saparauskas, J. (2019b). The evolution of “Technological and Economic Development of Economy": A bibliometric analysis. Technological and Economic Development of Economy, 25(3), 369-385. https://doi.org/10.3846/tede.2019.10193

Yu, D. M., Liu, H. N., \& Bresser, C. (2018). Peak load management based on hybrid power generation and demand response. Energy, 163, 969-985. https://doi.org/10.1016/j.energy.2018.08.177

Yu, D. M., Liu, H. N., Yan, G. G., Jiang, J., \& Le Blond, S. (2017). Optimization of hybrid energy storage systems at the building level with combined heat and power generation. Energies, 10(5), 606. https://doi.org/10.3390/en10050606

Zhang, X. M., \& Zhou, G. G. (2019). A scientometric analysis of ecological footprint of water resources from 2006-2018. Ekoloji, 28(107), 1539-1549.

Zhang, Y. Y., Thenkabail, P. S., \& Wang, P. (2019). A bibliometric profile of the remote sensing open access journal published by MDPI between 2009 and 2018. Remote Sensing, 11(1), 91.

https://doi.org/10.3390/rs11010091 